\title{
COMPARATIVE EVALUATION OF THE MAJOR GROUPS OF MANUAL TOOTHBRUSHES EFFICIENCY AND THEIR EFFECT ON THE ORAL CAVITY HYGIENIC STATUS
}

\section{R.K. Fattal', O.N. Risovannaya', S.V. Melekhov², V.L. Popkov', D.A. Domenyuk ${ }^{4}$}

\author{
${ }^{1}$ Department of Therapeutic Dentistry, Kuban State Medical University, \\ Ministry of Healthcare of Russian Federation, M. Sedina str., 4, Krasnodar, \\ Russia, 350063. E-mail: corpus@ksma.ru, tel: +7861 2680210 \\ 2 Department of Dentistry Faculty of Advanced Studies and Retraining \\ Specialists, Kuban State Medical University, Ministry of Healthcare of \\ Russian Federation, M. Sedina str., 4, Krasnodar, Russia, 350063. \\ E-mail: stomatologia.fpk@gmail.com, tel: +7861 2680210 \\ ${ }^{3}$ Department of Prosthetic Dentistry, Kuban State Medical University, \\ Ministry of Healthcare of Russian Federation, M. Sedina str., 4, Krasnodar, \\ Russia, 350063. E-mail: corpus@ksma.ru, tel: +7861 2680210 \\ ${ }^{4}$ Department of general practice dentistry and child dentistry, Stavropol \\ State Medical University, Ministry of Healthcare of Russian Federation, \\ 310, Mira Street, Stavropol, Russia 355017. \\ E-mail:domenyukda@mail.ru, tel: +79188701205
}

ABSTRACT - There is a lot of importance attached currently to individual selection of hygiene products depending on the person's dental and hygienic status. This present study focused on the effectiveness of various toothbrushes, and involved 76 patients aged 18-35 years old with a good (OHI-S $=0-0.6)$ and a satisfactory (OHI-S $=0.7-1.6)$ levels of oral hygiene. The teeth periodont was assessed as healthy, healthy also implying mild gingivitis. All the brushes were divided into the following categories: depending on the bristles shape - cylindrical, needle-shaped, rubberized, textured; depending on the material - nylon, polyester; depending on the hardness - medium, soft.

The hygiene level was evaluated with OHI-S (Green, Vermillion, 1964) before, 1, 2 and 3 months after the tested toothbrushes were taken for use. A visual inspection and microscopy were carried out using a Levenhuk light microscope ( $4 \times$ magnification). The bristles quality was considered satisfactory if their tips had no sharp and uneven edges, and the surface was smooth. Based on the data obtained, the wear of the bristles is linked directly to the oral hygiene quality as the brush field shape changes significantly through the operation period. Using of a manual toothbrushes made of the Tynex brand nylon and the Curen brand polyester significantly improves the individual hygiene quality and allows recommending it use to patients seeking to increase cleaning efficiency and lengthen their durability.

KEY W ORDS - manual toothbrush, oral hygiene, hygienic status, dental plaque.

\section{INTRODUCTION}

There is research data available suggesting that dental plaque is one of the most significant etiological and pathogenetic factors for the development of caries and inflammatory periodontal diseases, while effective oral hygiene is the main way to remove it $[1-7]$. At the same time, incorrect methods of teeth cleaning and improper selection of toothpastes have an adverse effect on the hard tooth tissues thus contributing to a decrease in the hygiene quality, rapid development and complication of decay, as well as the development of non-carious lesions (wedge-shaped defects) [8-13].

The need for dental preventive measures in various parts of the Russian Federation is known to be up to $96.8 \%$. This situation is aggravated by a low dental health culture and poor patient compliance [14-16].

There are a large number of electric toothbrushes featuring different performance principles available now on the market; however, mostly due to economic reasons, manual toothbrushes in Russia still remain very popular $[17-19]$.

Nowadays, toothbrushes include natural bristles or synthetic fibers (nylon, setron, perlon, dederlon, polyurethane). However, compared with synthetic fiber, natural bristles reveal a number of issues - a median canal filled with microorganisms, trouble keeping the brush clean, the bristles impossible to be made perfectly smooth while processing the tips, and trouble making it stiff as much as needed [20]. Besides, the surface and the tips of such bristles cannot be polished or rounded, which makes them potentially traumatic (Fig. 1).

Different manufacturers use synthetic bristles of different thickness and configuration. Advanced technologies allow now producing bristles with twisted hairs (the twister type) and the so-called micro-texture bristle, which is made through applying microvillishaped polymer coating on each bristle. Structured bristles clean the teeth not with the tips only, yet also with their side surfaces, which increases the toothbrush efficiency. Based on the degree of the bristles hardness (increasing order), manual toothbrushes can be ranged as follows: very soft (marked as ultrasoft, extrasoft or sensitive); soft (soft); medium hardness (medium); hard (hard); very hard (extra hard). Young children (up to 3) should use toothbrushes with very 

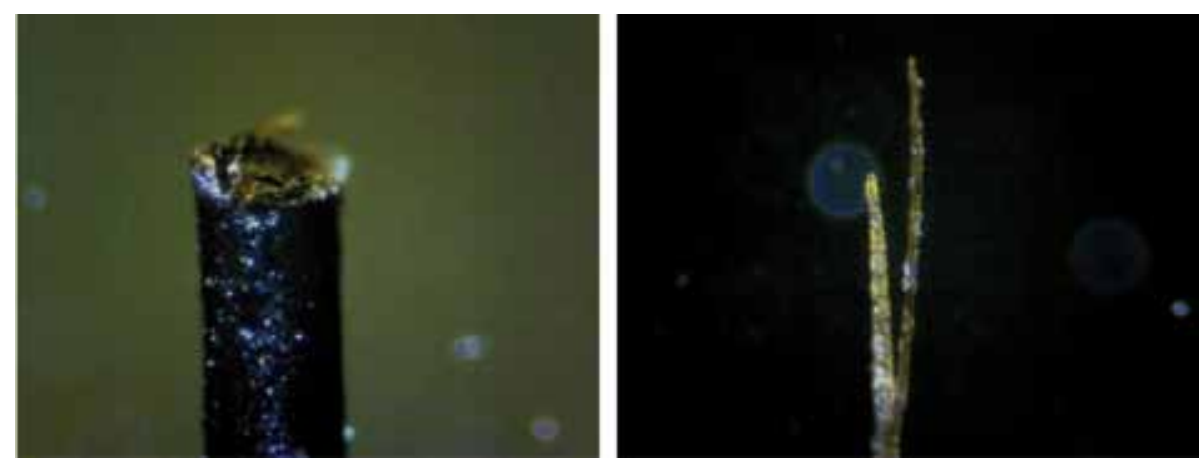

Fig.1. Microphotograph of pork bristle. Magnification $\times 4$

soft bristles, while for the preschoolers and primary schoolers soft toothbrushes are recommended. The best type of brushes for teens and adults are medium. However, in case of periodontal tissues inflammation, oral mucosa diseases and non-carious lesions of hard dental tissues, soft toothbrushes are recommended. Brushes with hard bristles can only be used for a short course in case of a tendency to an increased development of plaque. Medium and soft brushes are most effective, their bristles being more flexible and penetrating better into the interdental spaces, tooth fissures and subgingival areas. In many cases nowadays, manufacturers combine bristles of different hardness - the harder ones (they are often made shorter) central bristles are to clean effectively the chewing surface of the teeth, whereas the softer (and often longer) peripheral bristles clean the teeth perigingival areas [21].

The degree of brush hardness is largely due to the thickness of the bristles. Nylon bristles of medium hardness, for instance, have a diameter of about 0.20 $\mathrm{mm}$, soft ones $-0.15-0.18 \mathrm{~mm}$. When combining bristles of different hardness in one brush, they sometimes may be marked with different colors. However, manufacturers often use bristles with different fiber diameters yet indicate one degree of hardness. By the type of the tips processing, bristles can be rifled, polished, rounded, ground, combined. The rounded tips of the bristles will not only increase the cleaning capacity of the toothbrush, but also will prevent damage to the tooth enamel, periodontal tissues and oral mucosa. Synthetic bristles made from materials available nowadays can be processed very well, due to which bristles with cone-shaped rounding and ultrathin tips can be obtained, which in turn offers better penetration into natural deepening in the tooth enamel.

Most studies focus on comparison of the features specific of manual and electric toothbrushes, their effectiveness and safety, as well as the capacity to eliminate issues pertaining to gingivitis, never taking into account the material and shape of the bristles [22]. The authors here believe that effective removal of plaque and maintaining oral hygiene at a proper level will be achieved not only through the development of correct manual skills, yet also by due selection of personal products used to maintain oral cavity hygiene [23]. The wide range of such hygiene products offered by national and foreign manufacturers stirs among many authors a lot of interest in identifying the optimal material and shape of toothbrush bristles, as well as identifying their best acceptable service life.

Aim of study

To improve the efficiency of oral hygiene by selecting the optimal material and shape of toothbrush bristles and identifying their acceptable service life.

\section{MATERIALS AND METHODS}

The study involved 76 patients aged $18-35$ years old with a good (OHI-S $=0-0.6$ ) and a satisfactory $(\mathrm{OHI}-\mathrm{S}=0.7-1.6)$ levels of oral hygiene. The teeth periodont was assessed as healthy, while bealthy also implied mild gingivitis. The study also included 10 popular manual toothbrushes of different size, shape, as well as the bristle hardness and material. To ensure more correct comparison in the future, depending on the bristles shape all the toothbrushes were conventionally divided into the following groups: cylindrical, needle-shaped and rubberized bristles (Table 1).

The total number of the toothbrushes included was 200,20 brushes per group. The study was conducted subject to the GOST R52379-2005 requirements (Good clinical practice), with a written consent obtained from each of the participants. Each patient underwent the standard training method to develop due teeth-cleaning skills (method by N.G. Pakhomov, 1982). Prior to the study, all the patients were trained to brush their teeth properly with the ROCS PRO toothpaste up until their level of oral hygiene could be regarded as excellent or good ( $0-0.6$ points by OHI-S index). To study the changes in the bristle structure when cleaning was performed improperly, an additional group was established, which included 20 different toothbrushes 
Table 1. Study groups and their characteristics

\begin{tabular}{l|l|l|l|l|l|l}
\hline № & Toothbrush name & Bristle shape & Bristle material & Bristle stiffness & Bristle length & Bristle thickness \\
\hline 1 & "Aquafresh family" & Cylindrical & nylon “Tynex" & medium & $0,95 / 1,1$ & 0,23 \\
\hline 2 & "Colgate $360^{\circ}$ Comprehensive Cleaning" & Cylindrical & nylon"Tynex" & medium & $0,8 / 1,2$ & 0,22 \\
\hline 3 & "Colgate $360^{\circ}$ Charcoal" & Acicular & nylon "Tynex" & soft & 1,1 & $0,23 / 0,15 / 0,01$ \\
\hline 4 & "Colgate Premier Whitening" & Cylindrical & nylon 612 & medium & 1,0 & 0,21 \\
\hline 5 & "CURAPROX 5460 Ultrasoft" & Cylindrical & polyester & soft & 0,9 & 0,1 \\
\hline 6 & "LACALUT aktiv" & Acicular & nylon"Tynex" & soft & $1,0 / 1,3$ & $0,2 / 0,11 / 0,01$ \\
\hline 7 & "ORAL-B PRO-EXPERT" & Cylindrical & nylon"Tynex" & medium & $1,0 / 1,1 / 1,2$ & $0,18 / 0,2$ \\
\hline 8 & "R.O.C.S. Black Edition" & Textured & nylon "Tynex" & medium & $0,8 / 1,3$ & $0,18 / 0,2$ \\
\hline 9 & "SPLATCOMPLETE" & Acicular & nylon"Tynex" & medium & 1,1 & $0,22 / 0,17 / 0,01$ \\
\hline 10 & "SPLATWHITENING" & Rubberized & nylon"Tynex" & medium & 1,1 & 0,22 \\
\hline
\end{tabular}

( 2 brushes from each group). Throughout the study (3 months), these brushes were used by patients cleaning their teeth mostly with horizontal movements and exerting excessive pressure on the brush.

Prior to use, the bristles on all the toothbrushes were subjected to microscopic inspection to assess the initial quality of the bristles. To do this, 50 bristles were cut from each brush (10 out of 5 different areas of the brush spot) (Fig. 2).

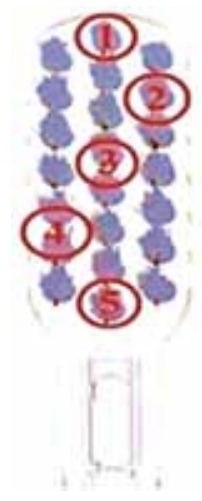

Fig. 2. Five areas of the brush spot where bristles were cut for the study

Visual inspection and photographing was carried out using a Levenhuk light microscope (magnification $-4 \times)$. The quality of the bristles was considered satisfactory if their tip had no sharp and uneven edges, while the surface was smooth. Similarly, 1, 2 and 3 months into using the brushes, a comparative assessment of the bristles wear in each of the groups was carried out. To understand the link between the bristle wear and the oral hygiene quality, the patients of all groups were assigned a simplified index of oral hygiene (OHI-S; Green, Vermillion, 1964) before, 1, 2 and 3 months into using the toothbrushes. The data statistical analysis was carried performed following the variation statistics method with the identification of the mean value $(\mathrm{M})$, standard deviation $(\sigma)$. For statistical data processing, the statistical packages Microsoft Excel 2007 and Stat Soft Statistica v6.0 were used. The critical significance level when testing statistical hypotheses in this study was taken as 0.05 .

\section{RESULTS AND DISCUSSION}

The evaluation of the initial quality of the bristles in new toothbrushes revealed that the share of well-treated bristles in the study groups varied from $77.2 \%$ to $94.4 \%$. At the same time, the group with the Colgate Premier Whitening toothbrush (belongs to the economy-class) showed the worst results. The best quality of bristles was observed on the CURAPROX, R.O.C.S., and ORAL-B brushes (Table 2).

Cylindrical bristles in Colgate Premier Whitening brushes (Nylon 612) proved prone to deformation through use. By the end of Month 3 into use, the bristles revealed moderate longitudinal stratification. At the same time, the tips erasability in this group was the highest, and could be observed during the first month already. By the end of Month 3, many bristles (76\%) had had their tips significantly deformed $(\mathrm{p}<0.001)$ (Fig. 3, 4).

The cylindrical bristles made of the Tynex nylon proved to be more wear-resistant compared to Nylon 612 (number of unsatisfactory bristles by the end of Month 3 went up by $21.3 \%$ ).

Despite the thickness, polyester bristles showed good resistance to deformation, abrasion and stratification (increase in the number of unsatisfactory bristles by $20.4 \%$ by the end of Month 3$)(p<0.001)$ (Fig. 5, 6).

Needle-shaped bristles were most susceptible to deformations and stratification due to their minimal thickness. Through Month 1 already they showed the fiber dissociation reaching its significant degree by Month 3. Over a period of 3 months, the number of 
Table 2. Initial quality of bristles and their wear through use, $(M \pm m),(p \leq 0,05)$

\begin{tabular}{l|l|l|l|l|l}
\hline \multirow{2}{*}{ № } & \multirow{2}{*}{ Toothbrush name } & \multicolumn{4}{l}{ Percentage (\%) of bristles with satisfactory quality } \\
\cline { 3 - 6 } & & Before use & $\begin{array}{l}\text { After } 1 \text { month } \\
\text { of use }\end{array}$ & After 2 months of use & After 3 months of use \\
\hline 1 & "Aquafresh family" & $84,73 \pm 2,41$ & $75,63 \pm 1,67$ & $63,69 \pm 1,58$ & $57,27 \pm 1,01$ \\
\hline 2 & "Colgate 360 Comprehensive Cleaning" & $82,49 \pm 1,94$ & $75,24 \pm 1,52$ & $63,25 \pm 1,74$ & $54,18 \pm 1,32$ \\
\hline 3 & "Colgate 360 Charcoal" & $85,26 \pm 1,83$ & $54,37 \pm 1,46$ & $37,26 \pm 1,29$ & $15,62 \pm 0,87$ \\
\hline 4 & "Colgate Premier Whitening" & $77,23 \pm 1,79$ & $54,18 \pm 1,21$ & $36,68 \pm 1,14$ & $24,39 \pm 1,06$ \\
\hline 5 & "CURAPROX 5460 Ultrasoft" & $94,41 \pm 0,89$ & $84,83 \pm 1,19$ & $81,27 \pm 1,74$ & $74,88 \pm 2,13$ \\
\hline 6 & "LACALUT aktiv" & $77,65 \pm 1,46$ & $46,87 \pm 1,35$ & $19,61 \pm 0,66$ & $8,43 \pm 0,41$ \\
\hline 7 & "ORAL-B PRO-EXPERT" & $92,48 \pm 2,59$ & $86,84 \pm 1,72$ & $84,49 \pm 1,26$ & $80,07 \pm 1,61$ \\
\hline 8 & "R.O.C.S. Black Edition" & $92,84 \pm 2,31$ & $87,61 \pm 2,08$ & $82,34 \pm 1,44$ & $75,12 \pm 1,59$ \\
\hline 9 & "SPLATCOMPLETE" & $86,78 \pm 1,48$ & $53,12 \pm 1,14$ & $31,26 \pm 0,91$ & $14,36 \pm 1,02$ \\
\hline 10 & "SPLATWHITENING" & $85,29 \pm 1,64$ & $84,04 \pm 2,07$ & $80,47 \pm 2,23$ & $77,44 \pm 1,69$
\end{tabular}
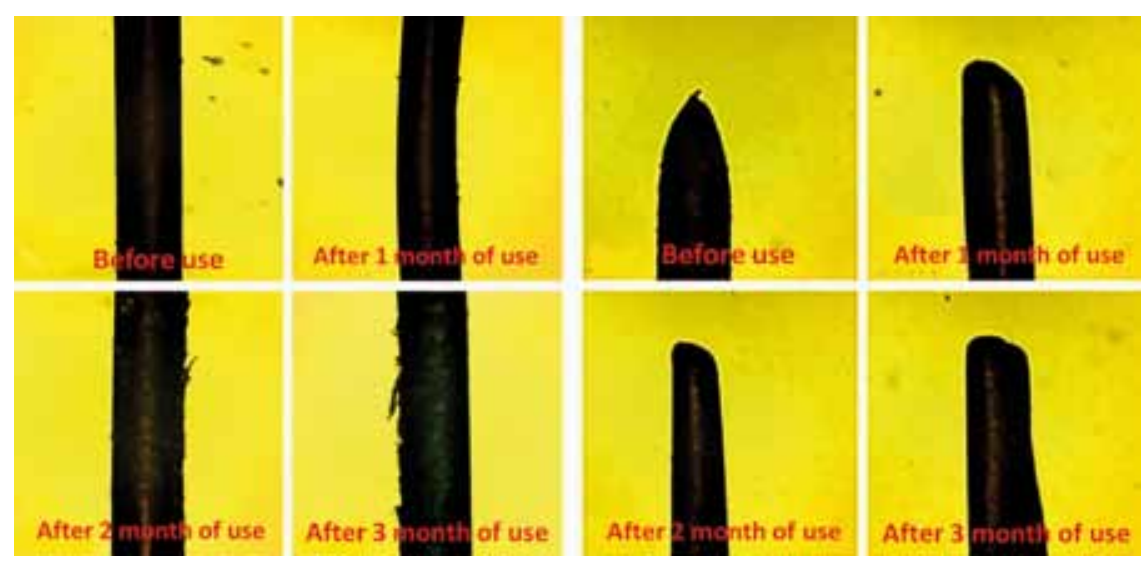

Fig. 3. External change in cylindrical bristles made of Nylon 612 at various stages of use (Colgate Premier Whitening). Magnification $\times 4$

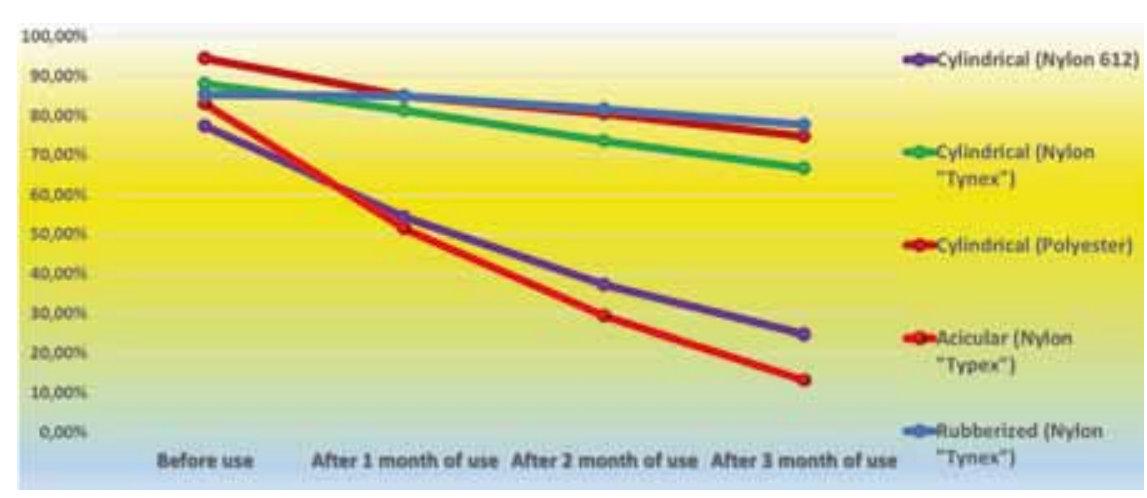

Fig. 4. Bristles wear-resistance depending on the material and shape within 3 months bristles with a quality level to be considered as unsatisfactory increased by $69.73 \%$ ( $p<0.001)$ (Fig. 4, 6).

Prior to use, rubberized bristles have a raised surface. There was no bristle stratification, abrasion, or deformations detected reliably through their use (an increase in the number of unsatisfactory quality bristles by $7.6 \%$ after 3 months) ( $p>0.05$ ) (Fig. 4). However, note to be made that this texture of the bristle surface is not as beneficial from the point of cleaning the bristles. Fig. 6 (2-B) shows toothpaste crystals accumulated in the bristles relief.

The results of dynamic changes in the oral cavity hygiene (based on OHI-S index) revealed a significant deterioration of oral hygiene in patients using brushes with needle-shaped bristles as early as by the end of Month 1. In most cases, the level of hygiene was 

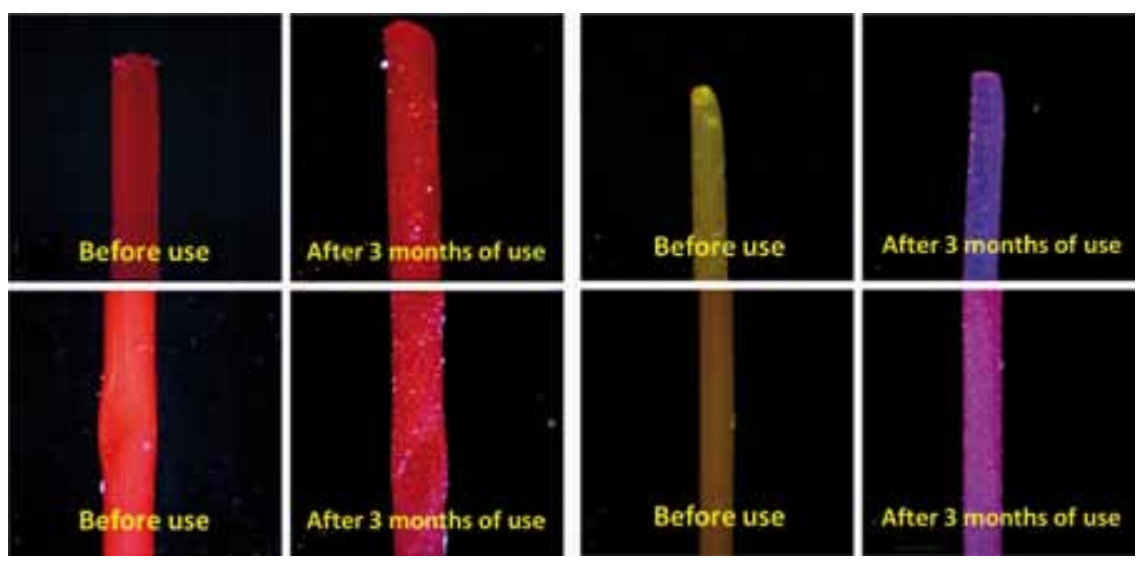

Fig. 5. External change in textured Tynex nylon bristles, R.O.C.S. Black Edition (1) and polyester bristles CURAPROX 5460 Ultrasoft (2) through various stages of their use. Magnification $\times 4$.
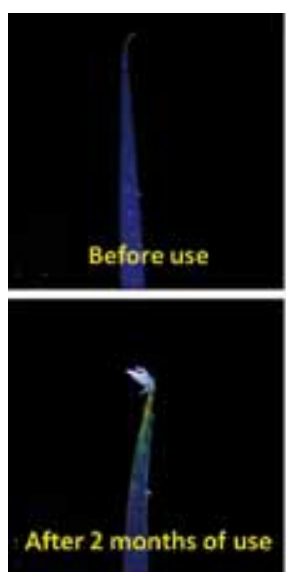
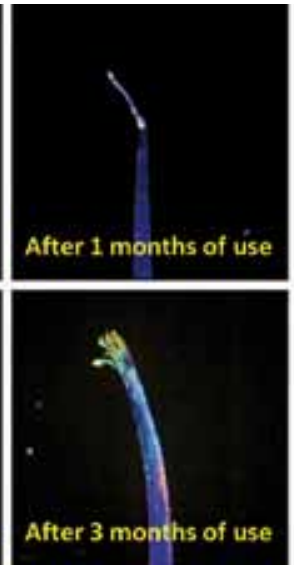
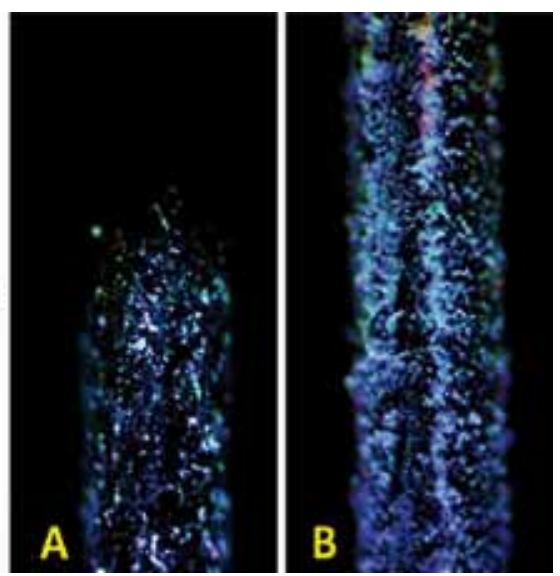

Fig. 6. External change in needleshaped bristles, LACALUTaktiv and SPLATCOMPLETE (1), and rubberized bristles, SPLATWHITENING (2) through various stages of their use.

$A$ - before use; $B$ - after 3 months. Magnification $\times 4$ rated as unsatisfactory (up to 2.5 points). By the end of Month 3, these values exceeded 2.6 points $(\mathrm{p}<0.001)$. A similar dynamics was observed in the group using cylindrical bristles made of Nylon 612 (Table 3).

The patients using toothbrushes with cylindrical and rubberized bristles made of Tynex nylon featured no significant change in the hygiene level ( $p>0.05$ ). The group of patients using improper brushing techniques showed that in addition to the visible deformation of the bristles, their significant dissociation was also present. These changes were to be seen already through Month 1, and were significantly aggravated by Months 2 and 3 . At the same time, the bristles had their edges getting sharp (Fig. 8).

\section{CONCLUSIONS}

1. The quality of bristles depends on the manufacturing material. The best processing quality was observed in bristles made from the Tynex nylon and polyester by Curen.

2. The wear-resistance of bristles directly depends on the thickness, shape and material. Nylon 612 showed a poorer resistance to abrasion than other materials. The most resistant to stratification were cylindrical bristles, made of the Tynex nylon.

3. Needle-shaped bristles are prone to deformation and stratification by as soon as 1 month into use. This feature will not allow enjoying the advantage offered by the bristles shape, which provides free penetration into harder-to-clean areas.

4. Polyester bristles are most prone to stratification in case of improper brushing techniques are employed. However, they featured good abrasionresistance despite their small thickness.

5. Bristles with rubber coating have good wearresistance, yet have a rough surface, which may make their cleaning complicated.

6. The wear of bristles directly affects the quality of oral hygiene, as the use of toothbrushes changes significantly the shape of the brushing field, which is due to the pressure exercised by the bristles on the teeth surface, so in old brushes the bristles contact spot around the precervical part of the tooth will be incomplete thus making cleaning improper.

7. Using a manual toothbrush made from the Tynex brand nylon and the Curen brand polyester will 
Table 3. Dynamic change in the oral hygiene, $(M \pm m),(p \leq 0,05)$

\begin{tabular}{l|l|l|l|l|l}
\hline \multirow{2}{*}{$№$} & \multirow{2}{*}{ Toothbrush name } & \multicolumn{3}{|l}{ Indicators hygienic index OHI-S } \\
\cline { 3 - 5 } & Before use & After 1 month of use & After 2 months of use & After 3 months of use \\
\hline 1 & "Aquafresh family" & $0,48 \pm 0,04$ & $0,58 \pm 0,03$ & $1,48 \pm 0,08$ & $2,36 \pm 0,11$ \\
\hline 2 & "Colgate $360^{\circ}$ Comprehensive Cleaning" & $0,46 \pm 0,05$ & $0,52 \pm 0,04$ & $1,46 \pm 0,09$ & $2,35 \pm 0,08$ \\
\hline 3 & "Colgate $360^{\circ}$ Charcoal" & $0,32 \pm 0,03$ & $1,56 \pm 0,07$ & $1,98 \pm 0,11$ & $2,36 \pm 0,12$ \\
\hline 4 & "Colgate Premier Whitening" & $0,28 \pm 0,04$ & $1,52 \pm 0,08$ & $2,02 \pm 0,06$ & $2,56 \pm 0,09$ \\
\hline 5 & "CURAPROX 5460 Ultrasoft" & $0,44 \pm 0,06$ & $0,76 \pm 0,07$ & $1,24 \pm 0,09$ & $1,48 \pm 0,05$ \\
\hline 6 & "LACALUT aktiv" & $0,37 \pm 0,03$ & $1,88 \pm 0,09$ & $2,36 \pm 0,14$ & $2,72 \pm 0,13$ \\
\hline 7 & "ORAL-B PRO-EXPERT" & $0,52 \pm 0,05$ & $0,56 \pm 0,04$ & $1,42 \pm 0,07$ & $1,56 \pm 0,09$ \\
\hline 8 & "R.O.C.S. Black Edition" & $0,54 \pm 0,02$ & $0,77 \pm 0,06$ & $1,29 \pm 0,08$ & $1,58 \pm 0,07$ \\
\hline 9 & "SPLATCOMPLETE" & $0,43 \pm 0,03$ & $1,86 \pm 0,08$ & $2,27 \pm 0,12$ & $2,67 \pm 0,09$ \\
\hline 10 & "SPLATWHITENING" & $0,39 \pm 0,02$ & $0,83 \pm 0,03$ & $1,18 \pm 0,06$ & $1,43 \pm 0,08$ \\
\hline
\end{tabular}

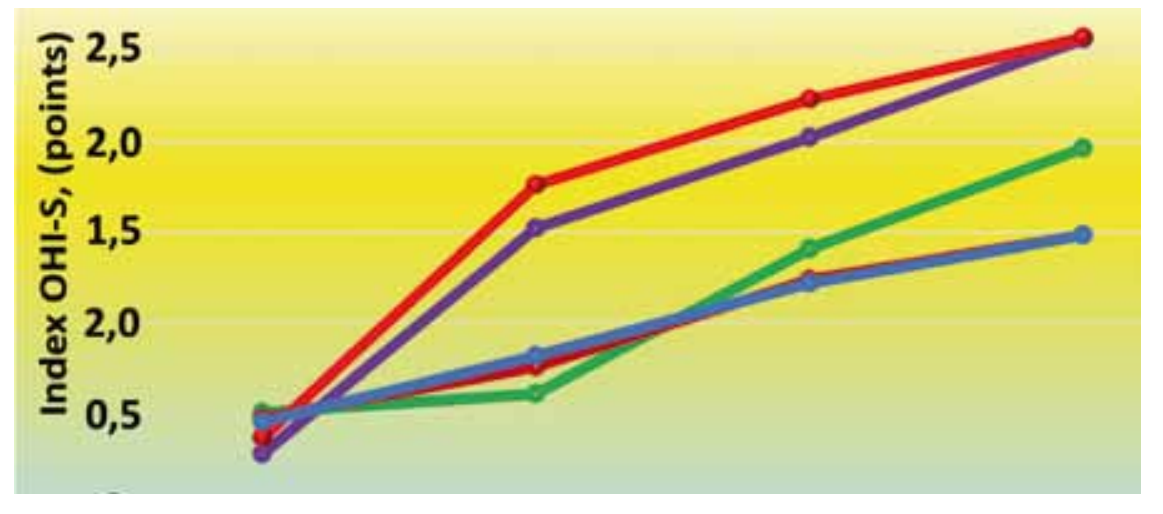

Fig. 7. Change in the oral hygiene level depending on the bristles shape and material through various stages of use
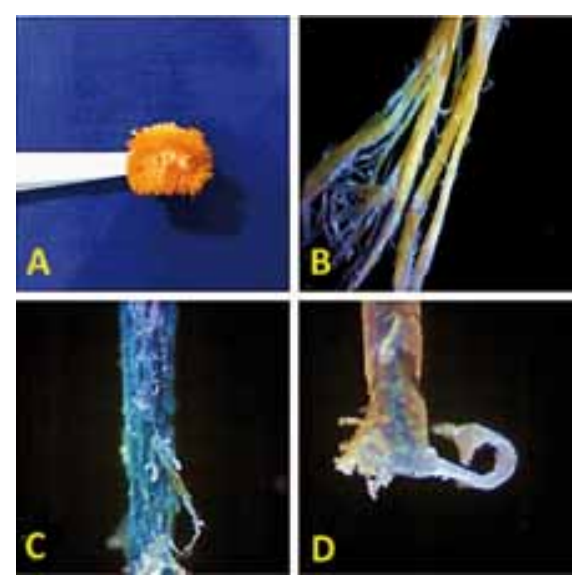

Fig. 8. Bristles after 3 month of improper tooth brushing. A - general view; $B, C, D$ - bristles stratification. Magnification $\times 4$ improve significantly the quality of individual hygiene, which allows recommending it to patients as a way to improve the cleaning effect as well as to extend the toothbrush service life.

\section{REFERENCES}

1. Lysova M.M., Lysov A.V., Solov'Eva O.A. Effect of the toothbrush on the rate of formation of plaque and calculus. Aktual'nye aspekty sovremennoj stomatologii i implantologii. 2017; 67-70. (In Russ.).

2. Domenyuk D.A., Zelensky V.A., Rzhepakovsky I.V., AnfinogENOva O.I., Pushkin S.V. Application of laboratory and x-ray gentral studies un early diagnostics of metabolic disturbances of bone tissue in children with autoimmune diabetes mellitus. Entomology and Applied Science Letters. 2018; 5(4): 1-12.

3. Bazikov I.A., Domenyuk D.A., Zelensky V.A. Semiquantitative evaluation of caries microflora in patients with dental and alveolar abnormalities and different severity of morphofunctional disturbances. Medical Bulletin of the North Caucasus. 2015; T. 10; 3(39): 238-241. (In Russ., English abstract). DOI: 10.14300/mnnc.2015.10055.

4. Domenyuk D.A., Davydov B.N., Zelensky V.A., Karslieva A.G. System analysis of risk factors for developing caries in children with dentoalveolar anomalies. Part II. Pediatric dentistry and prevention. 2014; Vol. 13; 4 (51): 51-60. (In Russ.) 
5. BYkov I.M., GilmiYarova F.N., Domenyuk D.A., DMitrienko S.V., IVANyuta S.O., Budaychiev G. M-A. Evaluation of cariogenic situation in children with type 1 diabetes mellitus given the mineralizing potential of saliva and enamel resistance. Kubanskij nauchnyj medicinskij vestnik. 2018; 25(4): 22-36. (In Russ., English abstract). DOI: 10.25207 / 1608-62282018-25-4-22-36.

6. DOMENYUK D.A., DAVYdov B.N., ZELENSKY V.A., Karslieva A.G. Optimizing the diagnosis of dental caries in patients with dental-anomalies based on the identification of prognostic factors (Part I). Institute of Dentistry. 2014; 3 (64): 37-39. (In Russ.)

7. Redinova T.L., Tret'Jakova O.V. Force of toothbrush pressure during tooth cleaning and its importance in the development of periodontal diseases. Parodontologija. 2016; 1: 53-7. (In Russ.).

8. Zimina Ju.I., Plotnikova S.Ju., Gerasimova T.V. Modern subjects and methods of individual oral hygiene. Sovremennye tendencii razvitija nauki i tehnologij. 2016; 4-3: 11-13. (In Russ.).

9. Domenyuk D.A., Zelensky V.A., DMitrienko S.V., Anfinogenova O.I., Pushrin S.V. Peculiarities of phosphorine calcium exchange in the pathogenesis of dental caries in children with diabetes of the first type. Entomology and Applied Science Letters. 2018; 5(4): 49-64.

10. DAvydov B.N., Domenyuk D.A., BYKov I.M., IVCHENKo L.G., DMitrienko S.V. Modern possibilities of clinical, laboratory, X-ray studies in preclinical diagnosis and prediction of the risk of developing periodontal diseases in children with diabetes mellitus type one. Part I. Periodontology. 2018; Vol. XXIV; 3-24 (88): 4-11. (In Russ.). DOI: 10.25636/ PMP.1.2018.3.1.

11. Revina A.S. Hygiene of the oral cavity as a factor of human health. Mezhdunarodnyj studencheskij nauchnyj vestnik. 2016; 2: 21. (In Russ.).

12. Domenyuk D.A., Davydov B.N., GilmiYarova F.N., Porfyriadis M.P., BudayChIEV G.M.-A. Optimization of pathogenetic therapy of caries of teeth in children sufficiating first type of diabeted diabetes, taking into account the methodological principles of personalized medicine (Part I). The Dental Institute. 2018; 81(4): 81-83. (In Russ.)

13. Domenyuk D.A., Davydov B.N., Zelensky V.A., KARSLIEVA A.G. System analysis of risk factors for developing caries in children with dentoalveolar anomalies. Part I. Pediatric dentistry and prevention. 2014; Vol. 13; 3 (50): 40-47. (In Russ.)

14. Abdusalamova B.F., Lapatina A.V., Pazdnikova N.K. Efficiency of using an electric sound toothbrush and device for cleaning interdental spaces. Dental Forum. 2016; 4: 10-11. (In Russ.).

15. Kisel'nikova L.P., Zueva T.E., Ogareva A.A. Changes in clinical parameters, microbiological indices and motivation for hygiene in children aged 5-12 years after the application of various toothbrushes. Klinicheskaja stomatologija. 2017; 1: 50-6. (In Russ.).
16. Domenyuk D.A., Davydov B.N., Zelensky V.A., Karslieva A.G. Optimizing the diagnosis of dental caries in patients with dental-anomalies based on the identification of prognostic factors (Part II). Institute of Dentistry. 2014; 4 (65): 60-63. (In Russ.)

17. Carev V.N., Omel'janenko N.P., Atrushkevich V.G. Comparative evaluation of the effectiveness of removing microbial biofilm from the tooth surface by electric toothbrushes with different types of rotation of the bristles. Parodontologija. 2017; 3: 19-23. (In Russ.).

18. Fedotova Ju.M., Kosjakina K.A. Motivation of young people when choosing oral hygiene products. Mezhdunarodnyj studencheskij nauchnyj vestnik. 2016; 6: 28. (In Russ.)

19. Orehova L.Ju., KudrJavceva T.V., Isaeva E.R. Influence of personal characteristics on the formation of features of individual oral hygiene. Evrazijskij sojuz uchenyh. 2016; 30: 72-77. (In Russ.).

20. Arid S., Alkan A., Arici N. Comparison of different tooth brushing protocols in poor-tooth brushing orthodontic patients. Eur. J. Orthod. 2007; 29(5): 488-92.

21. Montis K., Jenkins W., Hefti A. A randomized, parallel design study to evaluate the effects of a Sonicare and a manual toothbrush on plaque and gingivitis. J. Clin. Dent. 2008; 19(2): 64-68.

22. Chekunova O.I., Bat N.M. Use of pharmaco economic analysis in the selection of drugs for the departments of anesthesiology and resuscitation. Kubanskij nauchnyj medicinskij vestnik. 2008; 1-2: 96-99. (In Russ., English abstract).

23. Versteeg P.A., Piscaer M., Rosema N.A. Tapered toothbrush filaments in relation to gingival abrasion, removal of plaque and treatment of gingivitis. Int. J. Dent. Hyg. 2008; 6(3): 174-82. 